\title{
Cervical dystonia: about familial and sporadic cases in 88 patients
}

\author{
Distonia cervical: considerações sobre casos esporádicos e familiares em 88 pacientes \\ Carlos Henrique F. Camargo', Sarah Teixeira Camargos², Nilson Becker ${ }^{3}$, Renato Puppi Munhoz ${ }^{3}$, Salmo \\ Raskin ${ }^{4}$, Francisco Eduardo C. Cardoso², Hélio Afonso G. Teive ${ }^{3}$
}

\begin{abstract}
Cervical dystonia (CD) affects the musculature of the neck in a focal way or associated to other parts of the body. The aim of this study was to identify clinical differences between patients with dystonia patients without family history and with family history (sporadic). Eighty-eight patients with CD were recruited in a Movement Disorders Clinic between June of 2008 and June of 2009. Only patients with no etiological diagnosis were accepted for analysis. The age of onset of symptoms was later in patients with focal and segmental dystonia than in patients with generalized dystonia $(p<0.001)$. The severity of symptoms was higher in patients with sporadic dystonia than in familial patients $(p<0.01)$. Generalized cases were more severe in patients with a family history $(p<0.01)$. Sporadic patients had higher levels of pain than familial cases $(p<0.05)$. We expect soon to present the results of genetic analyzes of these patients.
\end{abstract}

Keywords: dystonia, cervical dystonia, DYT1, DYT6, genetic.

\section{RESUMO}

A distonia cervical (CD) afeta a musculatura do pescoço de modo focal ou em combinação com outras partes do corpo. 0 objetivo deste estudo foi identificar diferenças clínicas entre pacientes com distonia com história familiar e pacientes sem história familiar (esporádicos). Foram selecionados 88 pacientes com DC no Setor de Distúrbios do Movimento entre julho de 2008 e junho de 2009 . Somente os pacientes sem diagnóstico etiológico foram admitidos para análise. A idade de início dos sintomas foi mais tardia em pacientes com distonia focal e segmentar do que em pacientes com distonia generalizada $(p<0,001)$. A gravidade dos sintomas foi maior em pacientes com distonia focal esporádicos do que naqueles com história familiar ( $p<0,01$ ). Os casos generalizados foram mais graves nos pacientes com história familiar $(p<0,01)$. Pacientes esporádicos tiveram níveis maiores de dor em relação aos casos familiares $(p<0,05)$. Esperamos apresentar em breve resultados de análises genéticas desses pacientes.

Palavras-chave: distonia, distonia cervical, DYT1, DYT6, genética.

The definition of dystonia was recently revisited. Currently, dystonia is a movement disorder characterized by sustained or intermittent muscle contractions causing abnormal, often repetitive, movements, postures, or both. Dystonic movements are typically patterned, twisting, and may be tremulous. Dystonia is often initiated or worsened by voluntary action and associated with overflow muscle activation ${ }^{1}$. Most voluntary muscles can be affected and, in the case of the neck muscles, the condition is referred to as cervical dystonia (CD), the most common form of dystonia. The term spasmodic torticollis was previously used for this movement, but it does not stress the dystonic nature of the disease. CD can affect the musculature of the neck in a focal way or associated to other parts of the body ${ }^{2}$.

Over the past 20 years, several loci (DYT1 to DYT25) have been mapped in families with pure forms of dystonia, families with dystonia plus other movement disorders, or in sporadic cases of dystonia. The most different kinds of inheritance can be observed (autosomal dominant, autosomal recessive, and X-linked). However, only some genes for isolated (primary or pure) forms of dystonia were descripted until today ${ }^{3}$. Recently, CIZ1 (DYT23), ANO-3 (DYT24) and GNAL (DYT25)

\footnotetext{
1 Unidade de Distúrbios do Movimento, Serviço de Neurologia, Hospital das Clínicas, Universidade Federal do Paraná, Curitiba PR Brazil; Hospital Universitário, Universidade Estadual de Ponta Grossa, Ponta Grossa PR, Brazil;

¿Unidade de Distúrbios do Movimento, Serviço de Neurologia, Hospital das Clínicas, Belo Horizonte MG, Brazil;

Unidade de Distúrbios do Movimento, Serviço de Neurologia, Hospital das Clínicas, Universidade Federal do Paraná, Curitiba PR, Brazil;

${ }^{4}$ Genetika Laboratory and Pontifícia Universidade Católica do Paraná, Curitiba PR, Brazil.

Correspondence: Carlos Henrique F Camargo, Serviço de Neurologia - Hospital de Clínicas - UFPR. Rua General Carneiro, 181 CEP: $80060-900$ Curitiba PR Brasil.E-mail: chcamargo@uol.com.br

Conflict of interest: There is no conflict of interest to declare.

Received 02 October 2013; Accepted 09 October 2013.
} 
genes were associated to families with $\mathrm{CD}^{4,5,6}$. Before that, only TOR1-A (DYT1) and THAP1 (DYT6) genes were linked to isolated dystonia. Both are inherited as autosomal dominant traits, with reduced penetrance, and onset of clinical features commonly occurs during childhood or adolescence ${ }^{7-9}$.

Although these several loci and some genes were descripted in the last years, the presence of mutations in these genes in cohorts of patients with dystonia is low. For example, the presence of THAP1 mutations in families with earlier "primary" dystonia is about $25 \%{ }^{10}$. Regardless the monogenic inheritance, familial cases have lower mean age at disease onset than sporadic patients. Spread of dystonia to at least a second body site occurs more frequently in familial cases than in sporadic. The spread of symptoms is directly related to the duration of illness either in sporadic or in familial cases, however, in sporadic cases the most relevant spread occurs during the first 10 years; in familial patients, instead, progressive spread of dystonia occurs throughout the disease course ${ }^{11}$.

To identify clinical differences among familial and sporadic cases of $\mathrm{CD}$, we submitted patients at an evaluation in a Brazilian center for movement disorders.

\section{METHOD}

\section{Standard protocol approvals, registrations, and patient consents.}

All patients gave informed consent, and ethics approval was obtained from the medical joint and ethics committee at Federal University of Parana (UFPR) to perform this clinical and genetic study (CEP-UFPR ethical approval 1676.093/2008-06).

\section{Subjects selection and clinical assessment}

Subjects with CD who attended the Botulinum Toxin and Movement Disorders Outpatient Unit in the Neurology Service, Clínicas Hospital, UFPR, from June 2008 to June 2009, were selected for the study. Clinical diagnoses were made by means of history and examination by two neurologists. The patients were then assessed to identify clinical characteristics, an association with other movement disorders and neurological diseases, epidemiological data, the time during which the disease had evolved, a history of trauma, the use of medicines, signs and symptoms that might indicate a secondary cause and a family history of dystonia or other movement disorders. All the patients were submitted to brain computed tomography and cervical-spine radiography. Additional tests included complete blood count (CBC), TSH, VDRL, blood glucose test, ESR, electrolyte levels and liver and kidney function in all the patients. Computed tomography and magnetic resonance imaging of the cervical spine, magnetic resonance imaging of the brain and other laboratory tests were requested according to the clinical assessment of each patient. The inclusion criterion was: (1) the presence of CD without an established cause (a "primary" or a idiopathic dystonia). The exclusion criteria were: (1) presence of a cause for the CD (2) refusal to submit to diagnostic investigation; (3) inability to attend reassessment; and (4) failure to sign the informed consent form. CD was classified in accordance with established schemes ${ }^{1,12}$. The patients were assessed on admission to compare severity, disability and pain using the Toronto Western Spasmodic Torticollis Rating Scale (TWSTRS) and visual analog pain scale $(0=$ absence of pain, $1-3=$ mild pain, 4-6=moderate pain, 7-9=strong pain, $10=$ disabling pain).

\section{Statistics}

The distribution pattern for all the data was tested (normal or non-normal). The statistical differences between the means of the groups were measured using the one-tailed Student t-test for normal distributions and the MannWhitney test for non-normal distributions. For the differences between the expected values and the values actually found, the Fisher exact test was used. The results are given as mean \pm SD (standard deviation). The differences were considered significant if $\mathrm{p}<0.05$.

\section{RESULTS}

A total of 88 patients with CD were included, 56 were women and 32 men, a 1.75:1 ratio. Patients with familial history were called familial cases and those without familial history, sporadic cases. There were 16 families with $23(26.74 \%)$ patients (Table 1).

Among the patients, 36 (40.91\%) had focal CD. Other 22 (25\%) patients had segmental dystonia, 6 (28.57\%) with cranial-cervical dystonia, 13 (59.1\%) with arms-cervical dystonia, 3 (13.67\%) with arm-cranial-cervical dystonia, and one with laryngeal-cranial-cervical dystonia. Two (2.28\%) patients with multifocal dystonia had abnormal movement in their left leg. A generalized dystonia was observed in 28 $(31.81 \%)$ patients.

The mean age at onset of the group was $30.47 \pm 21.16$ years old (range, 5 months to 72 years old). The mean age at onset of focal dystonia (41.05 \pm 16.87 ), and segmental dystonia patients (35.55 \pm 24.13$)$, was higher than the generalized dystonia group, $12.36 \pm 9.10(\mathrm{p}<0.001)$. The incidence of generalized dystonia decreases, progressively, from the first decade to the fifth of life. In the seventh and eighth decades of life, there was only the onset of focal and segmental dystonia (Figure 1). The gender did not affect the onset of symptoms. The mean of onset in men was $28.01 \pm 21.66$ years old, and in women was $32.28 \pm 20.42$ years old $(\mathrm{p}=0.175)$. 
Table 1. Families with cervical dystonia.

\begin{tabular}{|c|c|c|c|c|c|}
\hline Family & Patient & Sex & Age (years) & Age of onset (years) & Clinical features and familial history \\
\hline \multirow[t]{2}{*}{1} & 1 & M & 24 & 20 & GD (CD, Meige syndrome, trunk, left leg). \\
\hline & 2 & M & 18 & 12 & $\begin{array}{c}\text { GD (CD, limbs, trunk and cranial dystonia). Several familial members with } \\
\text { different forms of dystonia. }\end{array}$ \\
\hline 2 & 3 & $\mathrm{~F}$ & 13 & 7 & GD (CD, trunk and limbs). Father, a cousin, and an uncle with dystonia. \\
\hline \multirow[t]{2}{*}{3} & 4 & M & 35 & 11 & GD (CD, limbs and trunk). \\
\hline & 5 & M & 30 & 10 & $\begin{array}{c}\text { SD (right arm, left arm and neck). The parents had consanguinity. Two cousins } \\
\text { had dystonia. }\end{array}$ \\
\hline \multirow[t]{2}{*}{4} & 6 & M & 92 & 70 & SD (Cervical and right arm dystonia). He presented Parkinsonism. \\
\hline & 7 & M & 68 & 56 & FD (CD). No Parkinsonism No other familial members affected. \\
\hline 5 & 8 & M & 10 & 4 & GD (CD, trunk and limbs). Two twins brothers with dystonia. \\
\hline 6 & 9 & $\mathrm{~F}$ & 47 & 30 & SD (CD, Meige syndrome and head tremor). Father with dystonia. \\
\hline 7 & 10 & $\mathrm{~F}$ & 40 & 5 & MD (left right and CD). She has a sister with dystonia in legs (most in right leg). \\
\hline 8 & 11 & M & 60 & 57 & $\begin{array}{c}\text { SD (CD, larynx, right arm and Meige syndrome). Sister and nice with } \\
\text { oromandibular dystonia and CD. }\end{array}$ \\
\hline 9 & 12 & $\mathrm{~F}$ & 47 & 39 & SD (CD and oromandibular). Several familial members with CD (focal form). \\
\hline 10 & 13 & $\mathrm{~F}$ & 31 & 9 & GD (CD, arms and trunk). A cousin had dystonia. \\
\hline 11 & 14 & $\mathrm{~F}$ & 33 & 12 & GD (CD, limbs and trunk). Her father had CD. \\
\hline 12 & 15 & F & 17 & 2 & $\begin{array}{l}\text { GD (CD, limbs, cranial region and trunk). She had mental retardation. Her } \\
\text { brother had CD without cognition features. The parents had consanguinity. }\end{array}$ \\
\hline 13 & 16 & M & 49 & 27 & GD (CD, larynx, left arm and trunk). \\
\hline \multirow[t]{2}{*}{14} & 17 & $\mathrm{~F}$ & 25 & 18 & SD (right arm, cervical and oromandibular dystonia). \\
\hline & 18 & F & 16 & 6 & $\begin{array}{l}\text { GD (CD, oromandibular, larynx, limbs and trunk) The grandmother had mild } \\
\text { face abnormal movements and speech disorder. }\end{array}$ \\
\hline \multirow[t]{4}{*}{15} & 19 & $\mathrm{~F}$ & 49 & 37 & FD (CD and head tremor). \\
\hline & 20 & $\mathrm{~F}$ & 27 & 25 & FD (CD and head tremor). \\
\hline & 21 & $\mathrm{~F}$ & 25 & 24 & FD (CD). \\
\hline & 22 & M & 18 & 17 & FD (CD). Grandmother with CD and head tremor. \\
\hline 16 & 23 & $\mathrm{~F}$ & 67 & 64 & $\begin{array}{c}\text { SD (blepharospasm and CD). She had Parkinsonism. Her nice had } \\
\text { blepharospasm. }\end{array}$ \\
\hline
\end{tabular}

M: male; F: female; CD: cervical dystonia; GD: generalized dystonia; SD: segmental dystonia; MD: multifocal dystonia; FD: focal dystonia.

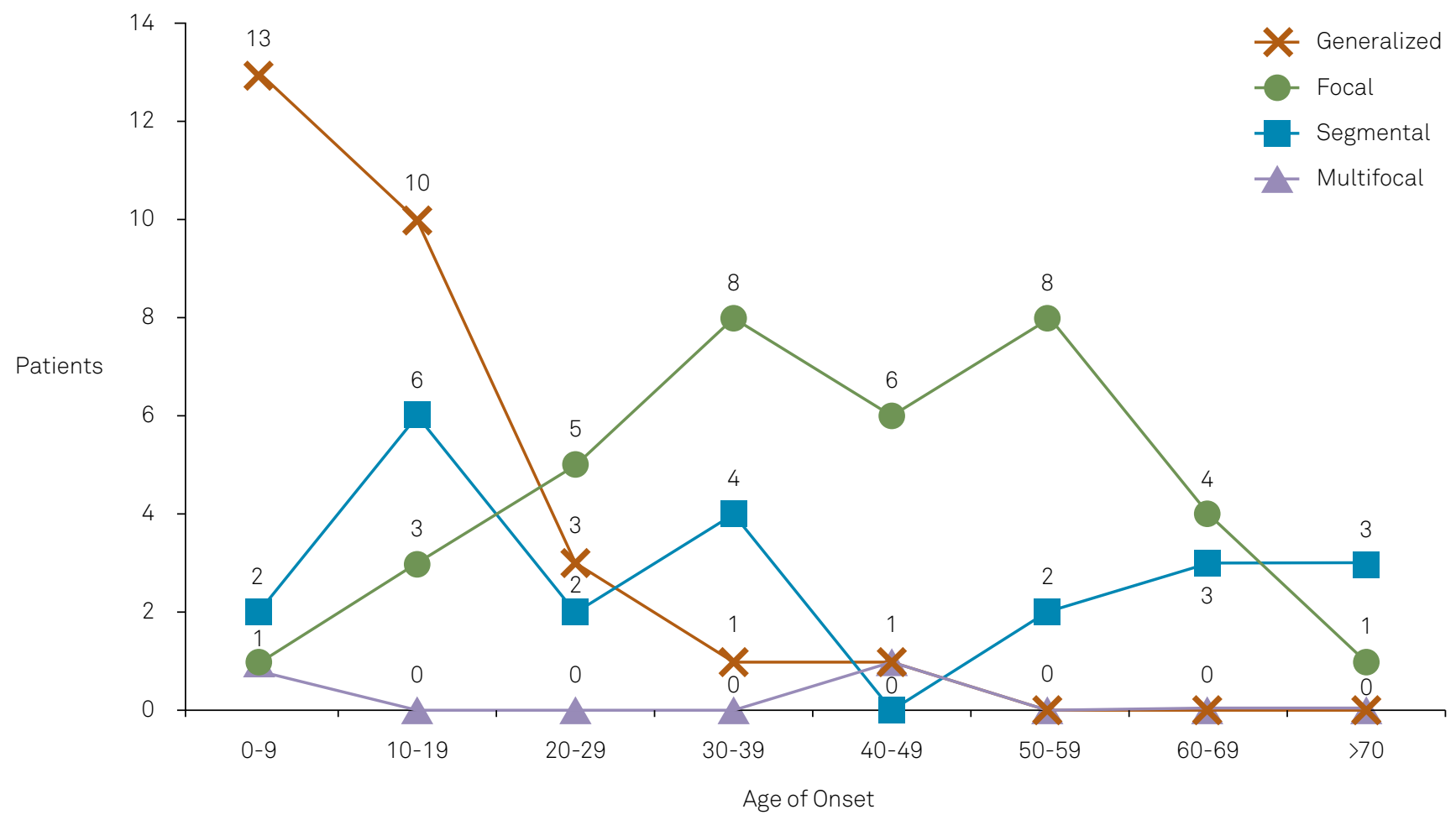

Figure 1. Incidence of cervical dystonia. 
Table 2. Differences between sporadic cases and familial cases of cervical dystonia

\begin{tabular}{|c|c|c|c|c|}
\hline Site of onset & Sporadic cases & Familial cases & Total & $p$ \\
\hline Patients & 65 & 23 & 88 & - \\
\hline Male:female ratio & $1: 1.95$ & $1: 1.3$ & $1: 1.75$ & - \\
\hline Age of onset* & $32.37 \pm 21.09$ & $24.78 \pm 20.48$ & $30.47 \pm 21.16$ & $p=0.07$ \\
\hline $\begin{array}{l}\text { Age of onset } \\
\text { Focal dystonia }\end{array}$ & $42.45 \pm 16.89(23)$ & $32.2 \pm 13.49(5)$ & $41.05 \pm 16.87(28)$ & $p=0.10$ \\
\hline Age of onset: segmental dystonia & $34 \pm 23.58(15)$ & $42 \pm 22.62(7)$ & $35.55 \pm 24.13(22)$ & $p=0.24$ \\
\hline Age of onset: multifocal dystonia & $42(1)$ & $5(1)$ & $24.5 \pm 24.75(2)$ & - \\
\hline Age of onset: generalized dystonia & $13.12 \pm 9.93(18)$ & $11 \pm 7.16(10)$ & $12.36 \pm 9.10(28)$ & $p=0.28$ \\
\hline Focal dystonia: generalized dystonia ratio & $1.83: 1$ & $1: 2.2$ & $1: 1$ & $p=0.227$ \\
\hline
\end{tabular}

* Years.

The main differences between sporadic and familial cases are in Table 2 . The mean age at onset of dystonia in sporadic cases was $32.37 \pm 21.09$ years old, and $24.78 \pm 20.48$ years old in familial cases. Although there has not been any statistic difference, cases of generalized dystonia seen in the familial group were higher than in the sporadic group.

There was no difference, between familial and sporadic cases, related to the localization and the spreading of the dystonia. There was also no difference about the site of onset of symptoms among the patients with generalized dystonia (caudal or rostral, limbs or cranial-cervical) even in familial or sporadic cases $(\mathrm{p}=0.643$ to $\mathrm{p}=1)$ (Table 3$)$.

Regarding clinical presentations of CD (torticollis, laterocollis, retrocollis and anterocollis), one form was presented in $46(52.27 \%)$ patients, two forms in $36(40.9 \%)$ patients and three in $4(4.54 \%)$. Among patients with generalized dystonia, 19 (67.86\%) presented more than one form of dystonia. The most of patients with one form was found in a group with focal dystonia, 25 (65.8\%) patients. The torticollis was the most common CD presentation, in
Table 3. Site of onset of generalized dystonia (sporadic cases $X$ familial cases).

\begin{tabular}{lccc}
\hline Site of onset & Sporadic cases & Familial cases & Total \\
\hline Cranial-cervical & 5 & 4 & 9 \\
Cranial-facial & 1 & 1 & 2 \\
Cervical & 4 & 3 & 7 \\
Limbs & 12 & 7 & 19 \\
Arms & 5 & 4 & 9 \\
Legs & 7 & 3 & 10 \\
\hline
\end{tabular}

$64(72.73 \%)$ patients. The laterocollis was observed in 42 (47.73\%) patients. The $17(19.32 \%)$ patients with retrocollis, and the $11(12.5 \%)$ patients with anterocollis were found mixed with other forms, no isolated cases were observed. The most common one presented was torticollis plus laterocollis (Table 4).

The severity caused by motor neck features, measured for TWSTRS scale, was higher in sporadic cases with focal dystonia $(16.06 \pm 4.21)$ than in familial cases with focal dystonia

Table 4. Patients with cervical dystonia divided by clinical presentation.

\begin{tabular}{|c|c|c|c|c|}
\hline Presentation & Sporadic cases $(n=65)$ & Familial cases $(n=23)$ & Total $(n=88)$ & $p$ \\
\hline 1 Type & 34 & 12 & 46 & 1 \\
\hline Torticollis & 23 & 9 & 32 & \\
\hline Laterocollis & 11 & 3 & 14 & \\
\hline Retrocollis & 0 & 0 & 0 & \\
\hline Anterocollis & 0 & 0 & 0 & \\
\hline 2 Types & 27 & 10 & 37 & 1 \\
\hline Torticollis + Laterocollis & 10 & 5 & 15 & \\
\hline Torticollis + Retrocollis & 6 & 2 & 8 & \\
\hline Torticollis + Anterocollis & 3 & 2 & 5 & \\
\hline Laterocollis + Retrocollis & 6 & 0 & 6 & \\
\hline Laterocollis + Anterocollis & 2 & 1 & 3 & \\
\hline 3 Types & 4 & 1 & 5 & 1 \\
\hline Torticollis + Laterocollis + Retrocollis & 2 & 1 & 3 & \\
\hline Torticollis + Laterocollis + Anterocollis & 2 & 0 & 2 & \\
\hline
\end{tabular}




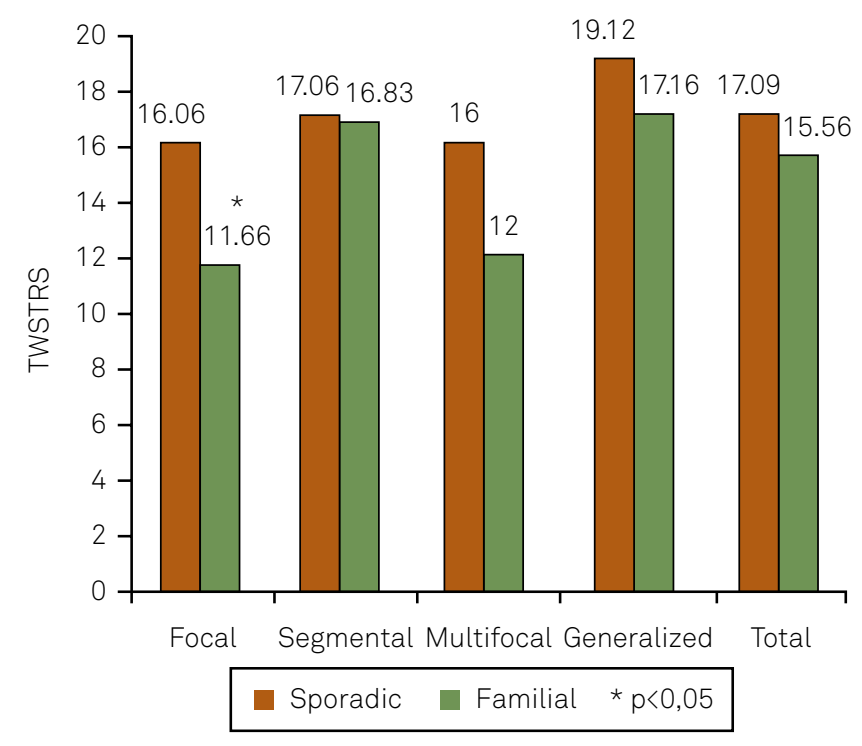

TWSTRS: Toronto Western Spasmodic Torticollis Rating Scale.

Figure 2. Differences of severity (TWSTRS) in cervical dystonia among patients with several clinical presentations.

$(11.66 \pm 7.56)(p=0.03$, Figure 2). There was no difference in severity between $\mathrm{CD}$ focal and $\mathrm{CD}$ segmental $(\mathrm{p}=0.13)$, and between $C D$ segmental and CD generalized $(p=0.19)$. When the same tool was used, patients with three or two forms of CD presented more severity than patients with one form of dystonia $(p<0.001)$. The generalized cases had more severity than focal cases $(p<0.05)$, mainly in familial patients $(p<0.01)$.

Pain in neck area was related by $53(60.23 \%)$ patients. 26 $(49.06 \%)$ related a strong or a disability pain. The jerks and spasms, in 13 (14.77\%) patients, were an aggravating factor to pain $(\mathrm{p}<0.001)$. The sporadic patients had higher pain levels than familial patients $(\mathrm{p}<0.05)$. There was more complaint of pain among patients with focal $\mathrm{CD}$ than patients with generalized $\mathrm{CD}(\mathrm{p}<0.05)$. The familial patients with focal $\mathrm{CD}$ related less pain than the sporadic patients with focal CD (Figure 3). There was more intensity of the pain in patients with two and three cervical movements than patients with one movement $(\mathrm{p}<0.05)$.

Tremor (head tremor and arms postural tremor) was observed in 32 (36.37\%) patients. Three patients, one with generalized and two with segmental dystonia presented parkinsonism. The patients with segmental dystonia were familial cases and started the features at 64 and 70 years old. The sporadic case started the symptoms at 17 years old by neck area with generalization in two years. No levodopa response was observed in these patients. Other four patients, two with segmental and two with generalized dystonia, had myoclonus. The mean age of onset was $15.5 \pm 5.07$ (range, 12 to 23 years), without familial history or other movement disorders. A partial response with alcohol was achieved in two patients. A familial history of movement disorder (tremor, dystonia or parkinsonism) was related to 26 (29.55\%) patients.

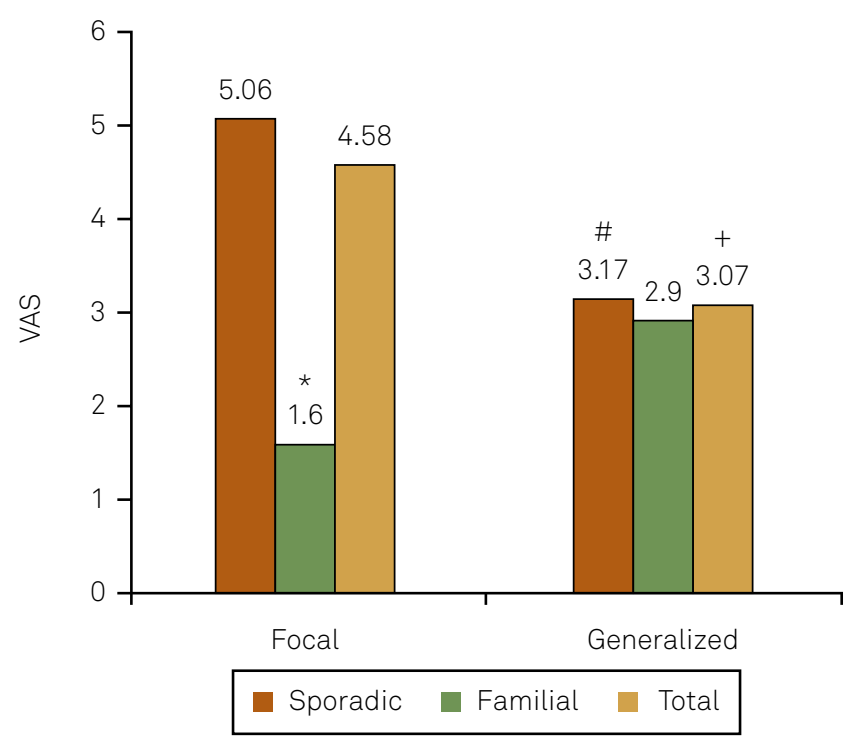

$+\mathrm{p}<0.05$ between the total of patients of focal dystonia and the total of patients of generalized dystonia;

\# $\mathrm{p}<0.05$ between the sporadic patients with focal dystonia and sporadic patients with generalized dystonia;

* $\mathrm{p}<0.05$ between the familial patients with focal dystonia and sporadic patients with focal dystonia.

VAS: visual analog scale.

Figure 3. Differences of pain level (VAS) in cervical dystonia among patients with several clinical presentations.

\section{DISCUSSION}

The total number of patients with familial history of movement disorders $(29.55 \%, 26.14 \%$ with familial history of dystonia) was below the $44 \%$ found by Jankovic et al. ${ }^{13}$, probably due to the difficulty of the majority of patients to access their relatives, due to social and economic level conditions, and the presence of unusual ethnic-related genetic transmission of dystonia in our region.

The relationship of some ethnic groups with specific types of dystonia is known. The DYT3 dystonia is a movement disorder of adult men from the Philippines. Dystonia DYT3 has only been diagnosed in the Philippines ${ }^{14}$. The frequency of dystonia is estimated at $1 / 9000$ in the Ashkenazi Jewish population ${ }^{15}$. Among other ethnic groups the prevalence is likely to be below, about $1 / 10000$ to $1 / 30000$, but has not been defined yet ${ }^{16}$. The DYT6 gene was described in a study of three Amish-Mennonite families. The DYT6 dystonia was initially associated with individuals of this ethnic group9. In 1880, the first Ashkenazi Jewish immigrants arrived in our region, mostly originating from Austrian Galicia. With the First and Second World War, new waves of Jewish immigrants arrived in Paraná ${ }^{17}$. The Mennonites formed an important wave of migration from Europe to the South of Brazil in XX century. Despite this fact, we cannot, by clinical history, establish a relationship of ancestry from any of the 88 patients evaluated with these ethnic groups. 
In agreement with previous studies, we found a predominance of CD in whites and females $(1: 1.75)^{13,18-21}$. There was an earlier onset of symptoms in men than in women at a mean of 5.18 years. Although statistical significance was not observed, these values were representative and higher than the difference of 2.2 years observed by Soland et $\mathrm{al}^{18}$.

The onset of symptoms occurred mainly between the fourth and the sixth decades of life $(61.2 \%)$ as demonstrated previously ${ }^{13,21}$. There was a tendency of earlier onset when there was a family history, particularly in focal dystonias, however, this finding was not confirmed statistically significant. Previous studies also pointed to an earlier onset of familial cases than sporadic cases ${ }^{11}$. Regardless family history, the generalized form started earlier, and focal and segmental forms later. In our study, patients started generalized dystonia mainly in childhood and adolescence, according previous studies ${ }^{11,13,21}$.

There is a rule in the study of dystonias. The ones which begin in early childhood tend to start in lower limbs and spread to the rest of the body, while the dystonia starting in adults usually begins in the upper half of the body and tend to remain focal ${ }^{22}$. With increasing age, there is a caudal-rostral pattern of the site of onset in the following order: lower limb dystonia, writer's cramp, CD, spasmodic dysphonia, and blepharospasm/oromandibular dystonia ${ }^{23}$. A study comparing the natural history of dystonia between sporadic and familial cases showed that the spread of symptoms to other sites could occur in both groups over time. However, a progression after five, 10, 15, 20 or 25 years were more pronounced in cases with familial history of dystonia ${ }^{11}$. We observed a higher number of patients with generalized dystonia in familial patients and a significant number of patients with higher focal dystonia in sporadic group. These data confirm a higher tendency of earlier onset with faster spreading of dystonia in familial patients than sporadic patients ${ }^{11,23}$.

The patients in our study who developed generalized dystonia began the symptoms in similar proportion by the limbs or the cranial-cervical region. There was not, unlike the previously published studies, a tendency of the familial generalized cases of starting their symptoms by legs ${ }^{11,23}$. According to previous studies, DYT1 dystonia has focal onset in the limbs, predominantly in the lower limbs, with subsequent generalization in childhood ${ }^{7,23}$. DYT3 dystonia has focal onset with secondary generalization in 2-5 years ${ }^{14}$. DYT5 dystonia, or dopa-responsive dystonia, is a generalized dystonia, with onset in the lower limbs, typically in childhood. In DYT7 and DYT13 dystonia, the onset is later, and dystonia remains a focal form. When DYT13 dystonia occurs in childhood, there is a greater tendency to generalize ${ }^{24,25}$. Although the main presentation of DYT6 dystonia is the onset in upper limbs in childhood spraying toward generalization, it may occur in the focal or segmental forms, having its onset in cranial-cervical region, and even occurring without a familial history ${ }^{10}$.
The most common presentation of CD was torticollis, followed by laterocollis, as demonstrated in previous studies $^{13,20,21}$. The presence of retrocollis was less common than the one reported in other series. In our study, patients with tardive dystonia were excluded. The retrocollis and involvement of other regions of the body in CD patients are more prevalent in patients with tardive dystonia. Torticollis and laterocollis, head tremor, geste antagoniste, and familial history are more common in dystonia "primary" ${ }^{26}$. In previous study presented by our group, including patients with multiple etiologies (8.25\% of cases secondary to the use of neuroleptics), the presence of retrocollis was higher $(37.6 \%)^{20}$.

Patients with two or three types of dystonic movements had severity and pain scores higher than those shown by patients with a single presentation. Generalized dystonia, with the majority of patients with more than one presentation, showed higher degrees of severity. Therefore, we reaffirm that a higher number of dystonic movements and extra-cervical sites of dystonia are factors of worsening to $\mathrm{CD}^{20}$. Another important observed datum is when familial patients remain with $\mathrm{CD}$ in focal form, tending to have milder features than sporadic patients.

This tendency was repeated when the neck pain was evaluated. The familial patients with focal CD had lower pain scores, which was statistically significant for patients with the sporadic form and focal CD. The high incidence of pain contributes significantly to the disability of the patients in CD, and distinguishes it from other focal dystonias ${ }^{21}$. Different degrees of pain in the neck region were reported by $60.23 \%$ of patients, similar to $63 \%$ and $75 \%$ previously described ${ }^{27,28}$.

$\mathrm{CD}$ can be diagnosed among the dystonia with gene loci known or not. Among the known loci with dystonia, CD can have early and familial onset with autosomal dominant inheritance (DYT1, DYT6 and DYT13), or early onset with autosomal recessive inheritance (DYT2 and DYT17), or late onset with autosomal dominant inheritance (DYT7, DYT21, DYT23, $D Y T 24$ and DYT25). Currently, despite of the identification of several loci related with dystonia, the TOR1A (DYT1), THAP1 (DYT6), CIZ1 (DYT23), ANO-3 (DYT24) and GNAL (DYT25) genes are the only ones linked to isolated ("primary") dystonias. The relationship of CIZ1 (DYT23), ANO-3 (DYT24) and GNAL (DYT25) genes with dystonia was descripted recent$\mathrm{ly}^{3-7,9}$, In each monogenetic inheritance dystonia, CD may be more or less common, and the onset can be part of the spreading even of the generalization ${ }^{3}$. The DYT23 dystonia, for example, has a pure latest onset $\mathrm{CD}^{4}$. Meanwhile, patients with DYT6 dystonia have a huge range of phenotypes, and wide range of age of onset ${ }^{8-10}$. Therefore, it is expected that CD may have several levels of pain and severity within the same etiology, but especially among the different etiologies.

Currently, these clinical analyses among different etiologies are not possible due to poor clinical details of the presentations of CD reported in studies aimed genetic analysis. 
Most likely, with the evolution of genetic studies of dystonia, it will be meaningless to compare clinical symptoms and pain of a familial group versus a sporadic group. In the future, the comparison of these parameters will be among groups with genetically defined etiology.
In conclusion, we descripted different clinical features, severity of symptoms and pain, between familial and sporadic patients with CD. This study was part of a continuous project. We expect to publish soon the first data about genetic evaluation of these patients to DYT1 and DYT6 genes.

\section{References}

1. Albanese A, Bhatia K, Bressman SB, et al, Phenomenology and classification of dystonia: a consensus update. Mov Disord 2013;28:863-873.

2. Tsui JK. Cervical dystonia. In: Tsui JK, Calne D (Eds). Handbook of distonia. New York: Marcel Dekker, Inc 1995:115-127.

3. Lohmann K, Klein C. Genetics of dystonia: what's known? What's new? What's next? Mov Disord 2013;28:899-905.

4. Xiao J, Uitti RJ, Zhao Y, et al. Mutations in ClZ1 cause adult onset primary cervical dystonia. Ann Neurol 2012;71:458-469.

5. Charlesworth G, Plagnol V, Holmström KM, et al. Mutations in ANO3 cause dominant craniocervical dystonia: ion channel implicated in pathogenesis. Am J Hum Genet 2012;91:1041-1050.

6. Fuchs T, Saunders-Pullman R, Masuho I, et al. Mutations in GNAL cause primary torsion dystonia. Nat Genet 2013;45:88-92.

7. Ozelius LJ, Hewett JW, Page CE, et al. The early-onset torsion dystonia gene (DYT1) encodes an ATP-binding protein. Nat Genet 1997;17:40-48.

8. Saunders-Pullman R, Raymond D, Senthil G, et al. Narrowing the DYT6 dystonia region and evidence for locus heterogeneity in the AmishMennonites. Am J Med Genet A 2007;143:2098-2105.

9. Fuchs T, Gavarini S, Saunders-Pullman R, et al. Mutations in the THAP1 gene are responsible for DYT6 primary torsion dystonia. Nat Genet 2009;41:286-288.

10. Bressman SB, Raymond D, Fuchs T, Heiman GA, Ozelius LJ, SaundersPullman R. Mutations in THAP1 (DYT6) in early-onset dystonia: a genetic screening study. Lancet Neurol 2009;8:441-446.

11. Elia AE, Filippini G, Bentivoglio AR, Fasano A, lalongo T, Albanese A. Onset and progression of primary torsion dystonia in sporadic and familial cases. Eur J Neurol 2006;13:1083-1088.

12. Fahn S, Bressman SB, Marsden CD. Classification of dystonia. Adv Neurol 1998;78:1-10.

13. Jankovic J, Leder S, Warner D, Schwartz K. Cervical dystonia: clinical findings and associated movement disorders. Neurology 1991;41:1088-1091.

14. Lee LV, Munoz EL, Tan KT, Reyes MT. Sex linked recessive dystonia parkinsonism of Panay, Philippines (XDP). Mol Pathol 2001;54:362-368.
15. Risch N, de Leon D, Ozelius L, et al. Genetic analysis of idiopathic torsion dystonia in Ashkenazi Jews and their recent descent from a small founder population. Nat Genet 1995;9:152-159.

16. Frédéric $\mathrm{M}$, Lucarz $\mathrm{E}$, Monino $\mathrm{C}$, et al. First determination of the incidence of the unique TOR1A gene mutation, c.907delGAG, in a Mediterranean population. Mov Disord 2007;22:884-888.

17. Gouvêia RR. Comunidade judaica de Curitiba, 1889-1970. Dissertação de Mestrado. Curitiba: PPGH/CNPq/Departamento de História da UFPR, 1980.

18. Soland VL, Bhatia KP, Marsden CD. Sex prevalence of focal dystonias. J Neurol Neurosurg Psychiatry 1996;60:204-205.

19. Almasy L, Bressman SB, Raymond D, et al. Idiopathic torsion dystonia linked to chromosome 8 in two Mennonite families. Ann Neurol 1997;42:670-673.

20. Camargo $\mathrm{CH}$, Teive HA, Becker N, Baran MH, Scola RH, Werneck LC Cervical dystonia: clinical and therapeutic features in 85 patients. Arq Neuropsiquiatr 2008;66:15-21.

21. Chan J, Brin MF, Fahn S. Idiopathic cervical dystonia: clinical characteristics. Mov Disord 1991;6:119-126.

22. Weiss EM, Hershey T, Karimi M, et al. Relative risk of spread of symptoms among the focal onset primary dystonias. Mov Disord 2006;21:1175-1181.

23. O'Riordan S, Raymond D, Lynch T, et al. Age at onset as a factor in determining the phenotype of primary torsion dystonia. Neurology 2004;63:1423-1426.

24. Bentivoglio AR, Del Grosso N, Albanese A, Cassetta E, Tonali P, Frontali M. Non-DYT1 dystonia in a large Italian family. J Neurol Neurosurg Psychiatry 1997;62:357-360.

25. Bentivoglio AR, lalongo T, Contarino MF, Valente EM, Albanese A. Phenotypic characterization of DYT13 primary torsion dystonia. Mov Disord 2004;19:200-206.

26. Molho ES, Feustel PJ, Factor SA. Clinical comparison of tardive and idiopathic cervical dystonia. Mov Disord 1998;13:486-489.

27. Lowenstein DH, Aminoff MJ. The clinical course of spasmodic torticollis. Neurology 1988;38:530-532.

28. Kutvonen O, Dastidar P, Nurmikko T. Pain in spasmodic torticollis. Pain 1997;69:279-286 